\title{
Microcantilever sensors for fast analysis of enzymatic degradation of poly (D, L- lactide)
}

Bose, Sanjukta; Keller, Stephan Sylvest; Boisen, Anja; Almdal, Kristoffer

Published in:

Polymer Degradation and Stability

Link to article, DOI:

10.1016/j.polymdegradstab.2015.04.021

Publication date:

2015

Document Version

Peer reviewed version

Link back to DTU Orbit

Citation (APA):

Bose, S., Keller, S. S., Boisen, A., \& Almdal, K. (2015). Microcantilever sensors for fast analysis of enzymatic degradation of poly (D, L-lactide). Polymer Degradation and Stability, 119, 1-8.

https://doi.org/10.1016/j.polymdegradstab.2015.04.021

\section{General rights}

Copyright and moral rights for the publications made accessible in the public portal are retained by the authors and/or other copyright owners and it is a condition of accessing publications that users recognise and abide by the legal requirements associated with these rights.

- Users may download and print one copy of any publication from the public portal for the purpose of private study or research.

- You may not further distribute the material or use it for any profit-making activity or commercial gain

- You may freely distribute the URL identifying the publication in the public portal 


\title{
Microcantilever Sensors for Fast Analysis of Enzymatic Degradation of Poly (D, L-lactide)
}

Sanjukta Bose*, Stephan S. Keller, Anja Boisen and Kristoffer Almdal

\author{
Department of Micro- and Nanotechnology, Technical University of Denmark, DK-2800 Kongens \\ Lyngby, Denmark
}

\section{Corresponding Author}

Sanjukta Bose

Ørestads Plads 345B, Department of Micro- and Nanotechnology,

Technical University of Denmark, DK-2800 Kongens Lyngby, Denmark

*Email: $\underline{\text { sbos@nanotech.dtu.dk }}$

Telephone: +4545255759

Fax: +4545887762 


\begin{abstract}
In this work we have performed a detailed analysis of enzymatic degradation of amorphous poly (D, L-lactide) (PDLLA) by measuring the resonance frequencies of polymer coated microcantilevers before and after degradation. The miniaturized cantilever system provides a fast analysis of the biodegradation rate of PDLLA with a minute amount of sample and without the need of thermal and chemical acceleration. The degradation rate of the polymer has been estimated by multilayer cantilever theory and model simulation. A bulk degradation rate of $0.24 \mu \mathrm{g} \mathrm{mm}^{-2}$ hour $^{-1}$ is estimated which agrees well with values reported in literature. The role of enzyme concentrations, prehydration in buffer, surface morphologies of PDLLA films and adsorption time of enzymes on the rate of degradation has been investigated. An increase in degradation rate is observed with an increase in enzyme concentration and after pre-hydration in buffer. A polymer film with a non-uniform surface degrades faster than the uniform one due to the preference of enzyme attack at film defects. A threshold time of around 3 hours is estimated for irreversible enzyme adsorption on the polymer surface after which degradation can proceed even in buffer solution in the absence of enzyme.
\end{abstract}

KEYWORDS:

Microcantilevers

Spray coating

Resonance frequency

Enzymatic degradation

PDLLA 


\section{INTRODUCTION}

In recent years a lot of research has focused on polymers obtained from natural resources or having capability to degrade in natural environment and physiological conditions[1]. A number of polymers such as poly(lactide) (PLA), poly(glycolic acid) (PGA), poly(lactide-co-glycolides) (PLGA), polyhydroxyalkanoates (PHAs), poly(caprolactone) (PCL), and poly(butylene succinate) (PBS) have come up as biocompatible and biodegradable candidates with widespread applications in the biomedical field[2,3]. Among these biodegradable polymers PLA has gained a lot of importance due to the efficient production of its raw material, lactic acid, from sugars and starchy materials[4,5]. PLA has been used in various applications. For example, coatings on stents induce biocompatibility and eliminate immune response[6,7]. In controlled drug delivery, the therapeutic agent is incorporated into biodegradable polymeric carriers and as the polymer degrades the drug is released continuously. Therefore, the drug release kinetics can be tailored precisely by knowing the degradation profile of the polymer used[8]. Furthermore, biodegradable polymer implants and scaffolds for tissue engineering provide long term biocompatibility and eliminate the need for surgical removal[9,10]. This underlines the need for a thorough analysis of the degradation behavior of biodegradable polymers used in clinical applications.

Hydrolytic degradation plays a major role in all these applications. Hydrolytic degradation of the three stereo forms of PLA: poly(L-lactide) (PLLA), poly(D-lactide) (PDLA), and poly(DL-lactide) (PDLLA) has been studied and reported extensively over the past decades[4,5,11-16]. Hydrolysis reactions may be catalyzed by acids, bases, salts, or enzymes[10,15,17-20]. Williams first reported that hydrolysis of PLLA is catalyzed by proteinase K from Tritirachium album[21]. Later on, Ashley and McGinity confirmed the enzymatic degradation of PDLLA by proteinase K[22]. Thereafter enzymatic degradation of both the amorphous and the semi-crystalline form of PLA has 
been studied extensively[7,17]. PDLLA has been frequently used as drug delivery film for implants and temporary scaffold for tissue engineering[10]. Degradation of PLA with proteinase K occurs typically via four steps[23]: (i) diffusion of proteinase $\mathrm{K}$ from the bulk solution to the PLA surface, (ii) adsorption of the enzyme on the PLA substrate, (iii) catalysis of the hydrolysis reaction i.e. the cleavage of the ester bond of PLA, and (iv) diffusion of the soluble lactic acid as degradation product from the PLA substrate to the solution. Most of the studies have used conventional methods like measuring weight loss by gravimetry, size-exclusion chromatography (SEC), differential scanning calorimetry (DSC) and X-ray diffraction (XRD) for measuring degradation of PLA. In general degradation studies require a long time[24-26] ranging from several hours to a few months and are often performed at harsh conditions of high/low $\mathrm{pH}$ and elevated temperatures to accelerate the experiments[27]. As biodegradable polymer films are used in many emerging biomedical applications $[10,19]$ there is a growing need for a fast analysis of degradation behavior of polymer films at the microscopic level. In the last decade, atomic force microscopy (AFM)[28], surface plasmon resonance (SPR)[29] and quartz crystal microbalance (QCM)[7] have shown new approaches to detect biodegradation of PLA in the micro scale. Microcantilevers have already been demonstrated to be highly sensitive sensors for mechanical and thermal characterization of polymers [30]. Recently, we introduced cantilever based sensors as a tool to study enzymatic degradation of PLLA [31]. Both QCM and the micro cantilevers use the change in resonance frequency as an indicator of the degradation of a polymer film deposited on their surfaces. However, QCM measurements on polymers are typically limited to the thin film regime[7,32,33] (thickness less than $1 \mu \mathrm{m}$ ) and characteristics exhibited by thin polymer films often strongly differ from bulk material properties[10,34]. Furthermore, QCM analysis shows some limitations for inhomogeneous polymer layers[35]. Compared to that micro cantilevers are capable of characterizing polymer films with thicknesses of several microns and varied surface morphologies 
thus allowing probing macroscopic properties on a microscopic platform. In our initial experiments [31] it was concluded that coating homogeneity should be particularly improved for precise estimation of the degradation rate of the polymer.

In the present study we have used micrometer sized cantilevers to perform a considerably more detailed and systematic analysis of enzymatic degradation of thin biopolymer coatings by measuring the resonance frequency of the cantilevers before and after degradation. The miniaturized sensor system is highly sensitive towards biodegradation of minute amounts of polymer, resulting in a fast analysis of the degradation behavior without the need of thermal and chemical acceleration. Amorphous PDLLA is spray coated to form films on one side of the cantilevers which are then immersed for degradation in proteinase $\mathrm{K}$ in Tris- $\mathrm{HCl}$ buffer solution. The change in resonance frequency measured by a Laser Doppler vibrometer and the optical microscope images taken at regular time intervals reveal how the degradation of PDLLA proceeds in different conditions. The influence of varied enzyme concentrations, pre- hydration and of the time allowed for surface adsorption of enzyme on the enzymatic degradation of PDLLA is studied. By changing the spray coating parameters[36] both uniform and non-uniform PDLLA films are deposited on the silicon cantilevers and the biodegradation of films with different surface morphologies is investigated. Image analysis of the optical microscope images is conducted to monitor the dimensions of the PDLLA coating during degradation. Iterative finite element method (FEM) analysis is then carried out on a simulated cantilever model. Here, the resonance frequencies after degradation were used to determine the thickness of the polymer film, which allowed the calculation of the degradation rate.

\section{EXPERIMENTAL SECTION}

\subsection{Materials}


PDLLA (ester terminated , $\mathrm{M}_{\mathrm{w}} 16,000 \mathrm{~g} / \mathrm{mol}$ determined by Gel Permeation Chromatography based on polystyrene calibration standards), Trizma base, Trizma $\mathrm{HCl}$ and dichloromethane (b. p. $40^{\circ} \mathrm{C}$, $\rho 1.33 \mathrm{~g} / \mathrm{ml}$ at $20^{\circ} \mathrm{C}$ ) were purchased from Sigma Aldrich. Proteinase K (recombinant, PCR grade) was obtained from Roche Diagnosis GmbH, Germany and used as received. Arrays of 8 silicon cantilevers on one chip (Octo500D), each with length $\mathrm{L}=500 \pm 4 \mu \mathrm{m}$, width $\mathrm{w}=90 \pm 2 \mu \mathrm{m}$ and thickness $\mathrm{t}=5 \pm 0.3 \mu \mathrm{m}$ were purchased from Micromotive GmbH (Mainz, Germany).

\subsection{Methods}

\subsubsection{Spray Coating}

$0.5 \mathrm{wt} \%$ PDLLA solution in dichloromethane was used for spray coating in an Exacta Coat Ultrasonic Spraying System (Sonotek, USA) equipped with an AccuMist nozzle operated at a frequency of $120 \mathrm{kHz}$ with a generator power of $1.3 \mathrm{~W}$. The cantilever arrays were mounted onto a chip holder to ensure no movement of the cantilever chip during spraying. Spray coating of PDLLA was only done on the top surface of the cantilevers. The spray coating parameters were optimized to prepare uniform and non-uniform coating on the cantilever surface with an average roughness $\left(\mathrm{R}_{\mathrm{a}}\right)$ of about $\mathrm{R}_{\mathrm{a}}=200 \mathrm{~nm}$ and $\mathrm{R}_{\mathrm{a}}<80 \mathrm{~nm}$, respectively[36]. For preparing uniform film, the nozzlesubstrate distance was $15 \mathrm{~mm}$ with 10 spray-passes while for non-uniform film the nozzle-substrate distance was $45 \mathrm{~mm}$ with 20 spray-passes. Speed of spray of $10 \mathrm{~mm} / \mathrm{s}$, substrate temperature of $20^{\circ} \mathrm{C}$, infusion rate of PDLLA solution $0.1 \mathrm{ml} / \mathrm{min}$ and compressed nitrogen at 0.03 bar were maintained for both film types. The initial film thickness was in between 3-5 $\mu \mathrm{m}$.

\subsubsection{Enzymatic degradation}

For degradation studies, each chip was placed in a petridish filled with $5 \mathrm{ml}$ of $0.05 \mathrm{M}$ Tris- $\mathrm{HCl}$ buffer solution $\left(\mathrm{pH} 8.6\right.$ at $23^{\circ} \mathrm{C}$ ) containing various concentrations of proteinase $\mathrm{K}$ at $37^{\circ} \mathrm{C}$. Resonance frequency measurement and optical microscope imaging were performed at intervals of 
3 hours. For this, the chips were removed from the media, washed thoroughly with Milli-Q water to remove residues of soluble degraded products, enzymes, salts and other impurities and dried in vacuum. After characterization the chips were placed in fresh enzyme solution to restore the original condition of degradation. Alternatively, measurements were also conducted with 24 hours immersion of the cantilever chips in the degradation media. An enzyme activity assay was performed with Chromozym PL (Roche Diagonistics GmbH, Germany) to confirm no alteration of enzyme activity of proteinase $\mathrm{K}$ in the experimental time frame.

\subsubsection{Measurement of resonance frequency}

The resonance frequency $(f)$ of the fundamental mode of a cantilever depends on the effective mass $m_{\text {eff }}$ and the effective stiffness $k_{\text {eff }}[31,37]$ :

$$
f=\frac{1}{2 \pi} \sqrt{\frac{k_{e f f}}{m_{e f f}}}
$$

From (1), it is clear that the resonance frequency of the cantilever changes when a polymer layer is applied due to the change in the $k_{\text {eff }} / m_{\text {eff }}$ ratio. In a similar way, degradation of the PDLLA coating results in a shift of $f$ towards the reference value measured for the cantilevers before coating. For experiments performed in vacuum and assuming small cantilever deflections, the resonance frequency of a multi-layered cantilever can be approximated by[31,37]

$$
f=\frac{1}{2 \pi} \frac{\lambda^{2}}{L^{2}} \sqrt{\frac{\sum_{i} E_{i} I_{i}}{w \Sigma_{i} \rho_{i} t_{i}}}
$$

where, $L$ and $w$ are the length and width, and $E_{i}, I_{i}, \rho_{i}$ and $t_{i}$ the Young's modulus, the area moment of inertia, the density and the thickness of the i'th layer of the cantilever. For the first flexural mode $\lambda=1.8751$.

The resonance frequency of the first mode of the cantilevers was measured with a Laser Doppler Vibrometer (MSA-500, Polytec GmbH, Germany). The cantilever chips were placed on a piezoresistively actuated stage mounted in high vacuum at a pressure below $3 \times 10^{-5} \mathrm{mbar}$. The 
measured initial resonance frequencies of the blank cantilevers were $30 \pm 5 \mathrm{kHz}$. The large deviation was due to dimensional variations of the cantilevers. Therefore in all the experiments, each cantilever was characterized individually before and after coating with PDLLA to obtain the reference resonance frequencies of blank $\left(f_{b}\right)$ and coated $\left(f_{c}\right)$ devices respectively. For comparison of the initial shift in resonance frequency due to spray coating of polymer on the cantilevers and to accommodate for their dimensional variations, the relative resonance frequency shift $\left(\delta_{0}\right)$ was calculated by the following equation:

$$
\delta_{0}=\frac{f_{b}-f_{c}}{f_{b}} \times 100[\%]
$$

$\delta_{0}$ is used as relative frequency shift at degradation time, $t_{d e g}=0$ hour in all the plots presented in this paper. Similarly, after immersion in the degradation media, at specific time intervals, the resonance frequency $f_{t}$ was measured. For comparison of the shift in resonance frequency at different degradation conditions with respect to $f_{b}$, the relative resonance frequency shift $\left(\delta_{\mathrm{t}}\right)$ is reported by the following equations:

$$
\delta_{t}=\frac{f_{b}-f_{t}}{f_{b}} \times 100[\%]
$$

The subscript $t$ stands for the time of degradation i.e., $t_{d e g}=3,6,9$ hours etc. All the frequency measurements were repeated three times and the average of the data is reported.

\subsubsection{Image Analysis and estimation of degradation rates using FEM simulation}

The surface texture of the coated cantilevers before and after degradation was observed with an optical microscope $(\mathrm{OM})$ (Zeiss, Germany) in bright field mode. With the progress of degradation the dimensions of the polymer layer on the cantilever were changing such as the length, width and thickness of the coating. The change in thickness cannot be determined by the analytical model described in (2). Direct measurement of polymer thickness on cantilevers is a challenge. Therefore, 
an indirect method of measuring polymer thickness by FEM simulation was chosen instead. Image $\mathbf{J}$ software was used on the OM images to measure the dimensions of the cantilever and the change in lengths and widths of the PDLLA coatings during degradation. These values and the measured resonance frequency of the cantilever were used to determine the thickness of the PDLLA coatings on the micro cantilevers with an iterative finite element method (FEM) using COMSOL 4.4[38]. For this purpose, the cantilever was modelled as a perfectly rectangular structure, rigidly clamped in one end (Supporting information S1). For the coated cantilevers, another block with different material properties was added on top of the cantilever (S2). For the FEM simulation, mass densities and Young's modulus of silicon and PDLLA are considered to be $2329 \mathrm{~kg} / \mathrm{m}^{3}, 1240 \mathrm{~kg} / \mathrm{m}^{3}$ (taken from manufacturer's data sheet) and $170 \mathrm{GPa}, 3.2 \mathrm{GPa}[10]$ respectively. It was assumed that both the modulus and the densities remain constant throughout the experiment. The eigenfrequency of a silicon cantilever with a polymer layer on the top surface was simulated for an estimated thickness of the polymer film. The obtained eigenfrequency was then compared to the measured resonance frequency and the thickness of the polymer coating was iteratively adjusted until the difference of the computed and measured frequency values were below $0.1 \%$ compared to the measured frequency. The change in width and thickness was then used to determine the degradation rates of PDLLA in proteinase $\mathrm{K}$ for a particular degradation condition.

\section{RESULTS AND DISCUSSION}

The resonance frequencies of a coated cantilever after immersion in degradation media for various time are shown in Figure 1. The dashed line in Figure 1 indicates the initial resonance frequency of the blank cantilever. 


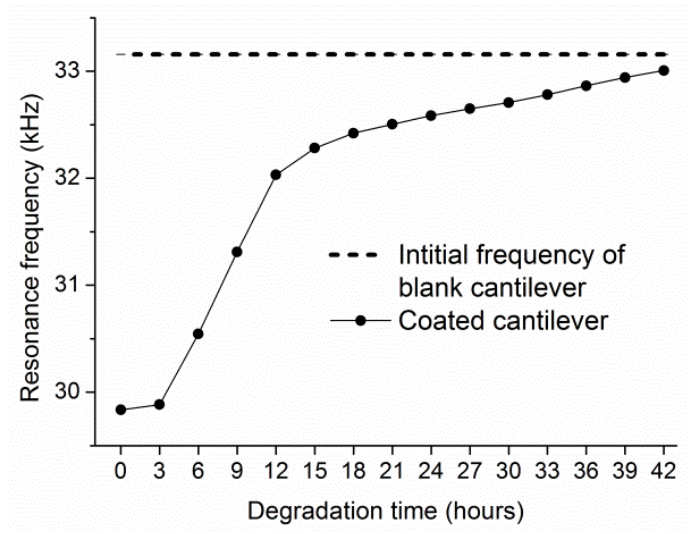

Figure 1. Resonance frequency a PDLLA coated cantilever during degradation in $50 \mu \mathrm{g} / \mathrm{ml}$ proteinase $\mathrm{K}$ at $37^{\circ} \mathrm{C}$. Initial frequency of the blank cantilever is shown by dashed line.

When the cantilever is coated with polymer the resonance frequency drops from $33.3 \mathrm{kHz}$ to $30.1 \mathrm{kHz}$ (Figure 1) due to the addition of mass on one side of the cantilever (equation (1)). When this cantilever is immersed in an enzyme solution of $50 \mu \mathrm{g} / \mathrm{ml}$ proteinase $\mathrm{K}$ at $37^{\circ} \mathrm{C}$, the amount of polymer on the cantilever surface decreases due to the onset of degradation and the frequency starts to increase until it approaches the initial resonance frequency of the blank cantilever.

\subsection{Concentration of enzyme solution}

The effect of varying concentrations of proteinase $\mathrm{K}$ on the degradation behavior of PDLLA is shown in Figure 2. 

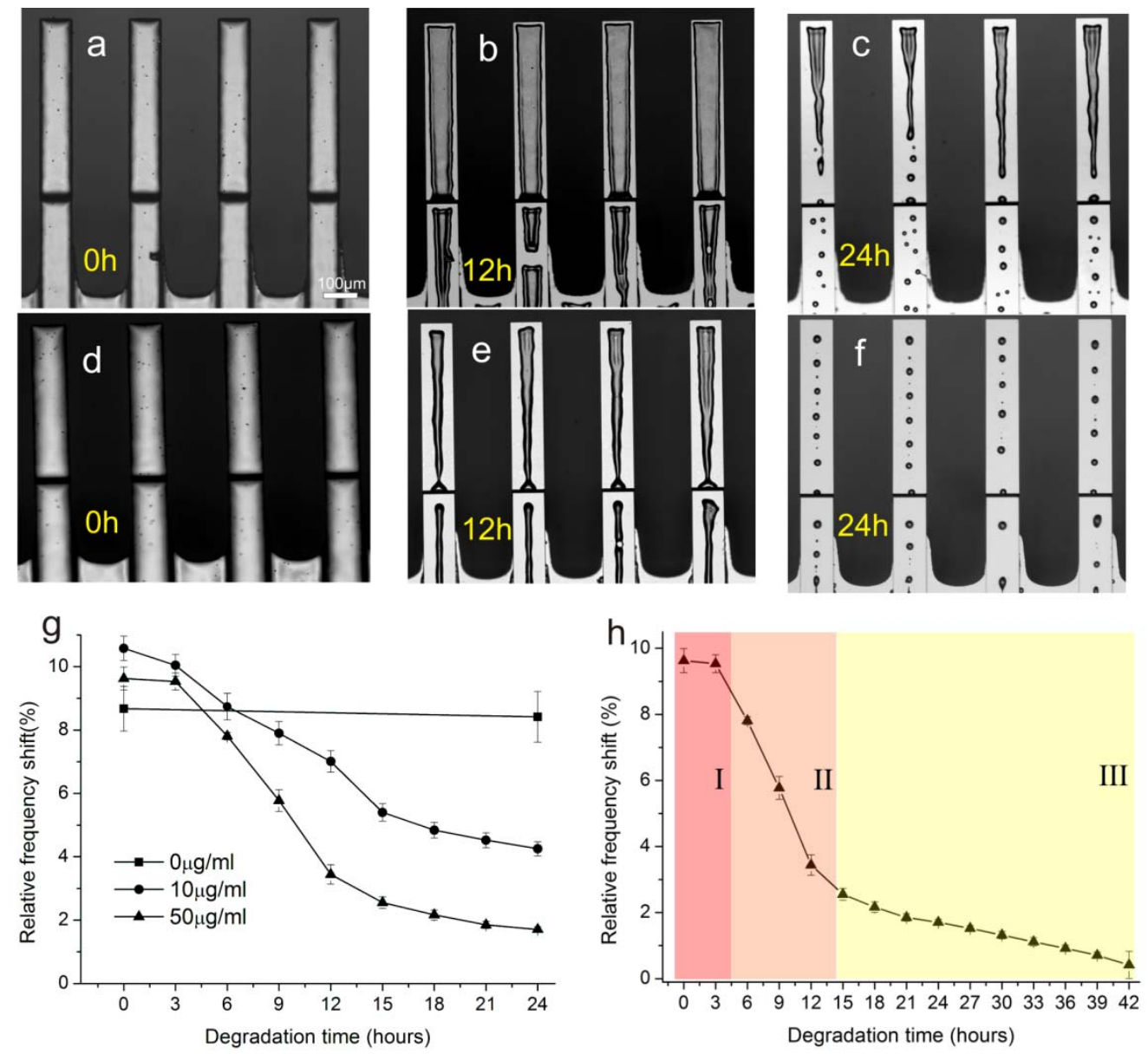

Figure 2. $\mathrm{OM}$ images of coated cantilevers (a-c) in $10 \mu \mathrm{g} / \mathrm{ml}$ proteinase $\mathrm{K}$ and (d-f) in $50 \mu \mathrm{g} / \mathrm{ml}$ proteinase $\mathrm{K}$ at $37^{\circ} \mathrm{C}$. Plots are shown for $(\mathrm{g})$ relative frequency shift $\left(\delta_{\mathrm{t}}\right)$ of coated cantilevers at different enzyme concentrations and (h) to illustrate the different regimes of degradation at $50 \mu \mathrm{g} / \mathrm{ml}$ enzyme concentration The scale bar shown in (a) is valid for all the OM images.

Figure 2 shows OM images of the PDLLA coated cantilevers at specified time intervals of degradation. Comparing Figure 2 (a-c) with Figure 2 (d-f) it is clearly observed that more PDLLA is degraded from the cantilever surface in the same time interval when increasing the enzyme concentration from $10 \mu \mathrm{g} / \mathrm{ml}$ to $50 \mu \mathrm{g} / \mathrm{ml}$. This is also reflected in the faster change in relative resonance frequency shift for the cantilevers (Figure $2 \mathrm{~g}$ ) exposed to $50 \mu \mathrm{g} / \mathrm{ml}$ of proteinase $\mathrm{K}$ compared to the ones exposed to $10 \mu \mathrm{g} / \mathrm{ml}$. In the control experiment, without enzyme $(0 \mu \mathrm{g} / \mathrm{ml})$ in the degradation media, there is no change in frequency. The higher the concentration of enzyme in 
the degradation media the higher is the amount of enzyme available to catalyze the ester hydrolysis step and hence a faster change in frequency is observed[7,32]. Figure $2 \mathrm{~h}$ shows that three main regimes can be identified for the measurement with $50 \mu \mathrm{g} / \mathrm{ml}$ of proteinase $\mathrm{K}$ at $37^{\circ} \mathrm{C}$.

For the first few hours of the experiment (regime I) the change of resonance frequency is very slow. It is then followed by an almost linear and relatively fast change of the resonance frequency up to $\sim 12$ hours (regime II). Then the change in frequency again slows down (regime III) and continues until the end of the measurement time frame. In regime I, the polymer coated chip is exposed to degradation media for the very first time. The polymer surface is hydrophobic and it is possible that the enzyme adsorption on the PDLLA surface before the initiation of the degradation reaction is hindered resulting in a very slow change in frequency. In regime II, a rapid decrease in the relative frequency shift indicates that the degradation is propagating very fast removing most of the polymer coating. In regime III, the polymer coating becomes discontinuous and eventually breaks into small islands of polymer (Figure 2c and 2f). Thereby the total coated area available for enzyme attack is reduced which in turn decreases the rate of relative shift in resonance frequency.

\subsubsection{Regime I: Pre-hydration effects}

To investigate the initial delay in regime I, coated cantilevers are immersed in Tris-HCl buffer solution for 3 hours (defined as prehydrated henceforth) before immersion in $50 \mu \mathrm{g} / \mathrm{ml}$ proteinase K solution.

Figure 3 shows a comparison between the relative shift in resonance frequency observed for PDLLA with and without pre-hydration in buffer solution before enzymatic degradation. 


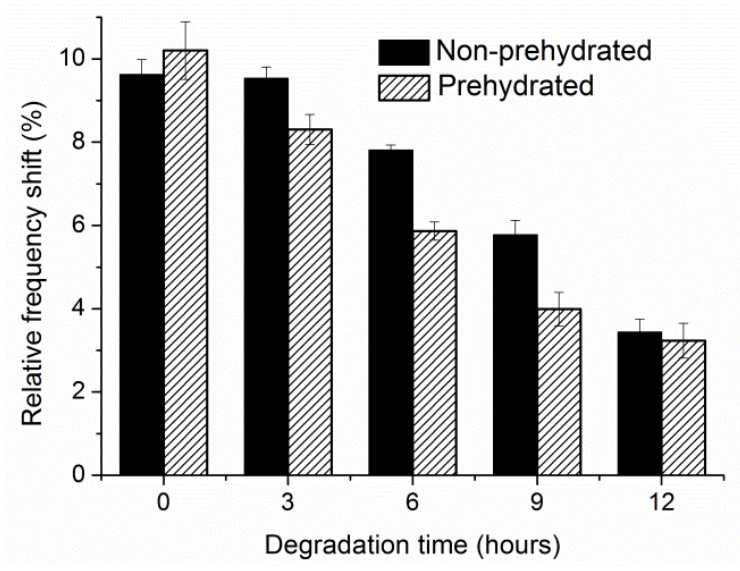

Figure 3. Relative frequency shift of prehydrated and non-prehydrated cantilevers when degraded in $50 \mu \mathrm{g} / \mathrm{ml}$ proteinase $\mathrm{K}$ at $37^{\circ} \mathrm{C}$.

From Figure 3, it is clearly observed that the cantilevers subjected to pre-hydaration are showing a faster decrease in relative frequency shift (hatched columns) than the devices that are directly immersed in enzyme solution (solid columns). The result is more prominent when the first data points after 3 hours are compared in Figure 3. It can be seen that there is almost no change in relative frequency shift for non-prehydrated cantilevers while there is a considerable decrease for the prehydrated ones.

Surface hydrophilicity is considered to be one of the important factors controlling the hydrolysability of biodegradable polymers. Surface modifications like alkaline treatment, coating, and surface grafting have been used as effective methods to control the biodegradability of polymers without affecting the bulk physical properties[10,39,40]. For alkaline treatment of PLLA prior to enzymatic degradation, mostly $\mathrm{NaOH}$ solution ( $\mathrm{pH}$ 12) has been used and it is reported that the cleavage of ester groups increases the number of hydrophilic hydroxyl and carboxyl groups on the surface thus increasing the surface hydrophilicity. In this study, most likely the pre-hydration for 3 hours in Tris- $\mathrm{HCl}$ buffer solution $(\mathrm{pH} \mathrm{8.6)}$ has modified the surface hydrophilicity of the PDLLA coating on the cantilevers which facilitates the enzyme attack when exposed to proteinase $\mathrm{K}$ 
solution. This might explain the initial delay in regime I (Figure $2 \mathrm{~h}$ ) when the cantilevers were directly subjected to enzymatic solution without pre-hydration.

\subsubsection{Regime II: Estimation of degradation rate}

The steep linear decrease in resonance frequency shift in regime II is used to estimate the degradation rate of PDLLA in $50 \mu \mathrm{g} / \mathrm{ml}$ proteinase $\mathrm{K}$ at $37{ }^{\circ} \mathrm{C}$. From $\mathrm{OM}$ images, the length and width of the coating is measured during degradation and FEM simulation is performed to estimate the thickness of the polymer layer as described earlier. The change in the measured width and calculated thickness of the PDLLA layer is shown in Figure 4.

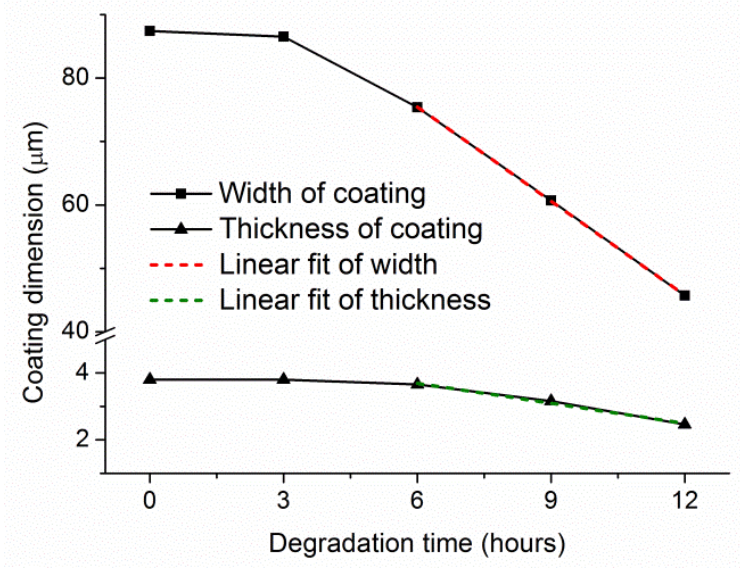

Figure 4. Change of dimension of PDLLA coatings on cantilevers during degradation with $50 \mu \mathrm{g} / \mathrm{ml}$ proteinase $\mathrm{K}$ at $37^{\circ} \mathrm{C}$.

From Figure 4, it is seen that both the width and thickness of the PDLLA coating are changing simultaneously but at different rates. The dimensional change is almost negligible in regime I. In regime III, the continuity of the film is lost and simulation was omitted. The degradation rates are calculated from the slope of the curve showing the change in width and thickness in regime II .

Two different rates are observed in this study: i) A lateral degradation rate corresponding to the change in width of the film which is also visible from the OM images in Figure 2 and ii) a vertical 
degradation rate corresponding to the change in thickness of the film. The lateral degradation rate is found to be $\sim 2.5 \mu \mathrm{m} /$ hour whereas the vertical degradation rate is $\sim 0.2 \mu \mathrm{m} /$ hour as calculated from the slope of the thickness plot against degradation time. The vertical degradation of the PDLLA coating is considered equal to the bulk degradation of the polymer. When calculated in terms of mass loss, the bulk degradation rate is $0.24 \mu \mathrm{g} \mathrm{mm}^{-2}$ hour ${ }^{-1}$. This agrees well with a rate of $0.28 \mu \mathrm{g} \mathrm{mm}^{-2}$ hour ${ }^{-1}$ for proteinase $\mathrm{K}$ degradation of PLA with $50 \%$ L-lactyl content i.e., PDLLA reported by Reeve et al[41]. for their specimen of dimension $2.5 \mathrm{~cm} \times 1 \mathrm{~cm} \times 0.06 \mathrm{~mm}$ and is also in range with rates reported by others[42].

Studies have shown that in enzymatic degradation, the enzymes prefer to attack at the structural defects present on the substrate, i.e. at the edges, or in cracks and holes of the polymer films or lipid monolayers[43-46]. In our case, the enzymes seem to start fast degradation at the interface between the silicon cantilevers and the PDLLA film at the edge of the cantilevers. For small features such as in stents coated with biocompatible polymer, this lateral degradation can play a major role too. The vertical degradation rate of biodegradable polymer film is of great importance in applications in the biomedical field. Drug release kinetics can be tailored knowing the degradation rate of the polymer matrix used in drug delivery systems.

\subsection{Surface morphology}

The observation of high degradation rates at edges and defects indicates that the surface morphology of the PDLLA coating might have a major influence on the degradation rate. Therefore, enzyme degradation of PDLLA coatings with different surface morphologies was investigated. For this purpose, the spray coating parameters were modified to produce both uniform and non-uniform PDLLA coatings on cantilevers. Figure 5 shows the OM images and relative shift in resonance frequency with respect to the blank cantilevers for both types of coatings. 

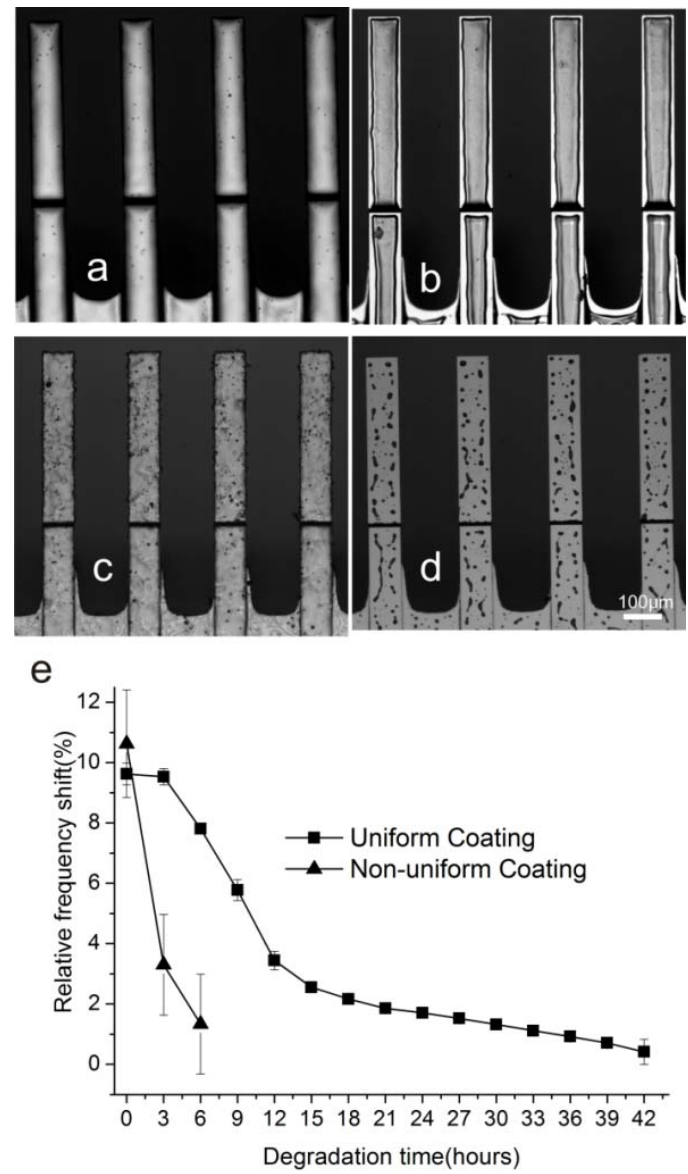

Figure 5. OM images of uniformly coated cantilevers at (a) $0 \mathrm{hr}$, (b) $6 \mathrm{hrs}$ and non-uniformly coated cantilevers at (c) $0 \mathrm{hr}$ and (d) $6 \mathrm{hrs}$ and the relative frequency shift (e) upon degraded in $50 \mu \mathrm{g} / \mathrm{ml}$ proteinase $\mathrm{K}$ at $37^{\circ} \mathrm{C}$. The scale bar shown in (d) is valid for all the OM images.

It is seen from Figure 5 that after 6 hours there is almost a complete removal of PDLLA from nonuniformly coated cantilevers (Figure 5d) when subjected to degradation in $50 \mu \mathrm{g} / \mathrm{ml}$ proteinase $\mathrm{K}$. Compared to that, the uniformly coated cantilevers (Figure 5b) are still mostly covered by PDLLA exposed to the same enzyme concentration for the same time. This observation is also confirmed by the almost $6 \mathrm{x}$ faster shift in the resonance frequency for the non-uniformly coated devices compared to the ones coated uniformly in Figure 5e.

This confirms that enzymes show preferential attack on edges or defects in the polymer films as discussed earlier. For the non-uniform coating, the surface of the PDLLA film (Figure 5c) is 
favorable for enzyme attack compared to the very smooth and intact film on the uniformly coated cantilevers (Figure 5a). In case of the uniformly coated cantilevers, degradation mainly propagates at the interface between the PDLLA film and the silicon cantilever surface at the edges of the cantilevers which acts as a defect at which the enzymes show higher ingression. The enzymes diffuse to the interfaces between the silicon and the PDLLA and catalyze the hydrolysis reaction at these interfaces which results in the lateral degradation. Similar observation has been reported by Tsuji et al. reporting selective degradation of PLLA in PCL-PDLLA blend films [47].

\subsection{Influence of enzyme adsorption time}

All the experiments discussed so far are conducted at the same time intervals and identical degradation conditions. Here, a new set of experiments is conducted varying the conditions for enzymatic degradation to study the influence of enzyme adsorption time. Degradation experiments are performed to find out the effect of different experimental conditions on the degradation during 24 hours as shown by the OM images and the relative frequency shift in Figure 6. Condition '24h E' (Figure 6) is when a PDLLA coated cantilever chip is immersed in enzyme solution and incubated continuously for 24 hours. Condition ' $3 \mathrm{~h} \mathrm{E}+21 \mathrm{~h} \mathrm{~B}$ ' and condition ' $1 \mathrm{~h} \mathrm{E}+23 \mathrm{~h} \mathrm{~B}$ ' (Figure 6) are coated cantilever chips immersed in enzyme solution for 3 hours and 1 hour respectively and then transferred without washing to buffer solution for 21 hours and 23 hours respectively to see the effect of the time available for surface adsorption of enzyme on the degradation of the PDLLA film. Condition ' $24 \mathrm{~h} \mathrm{~B}$ ' (Figure 6) is a control experiment where a coated chip is immersed in buffer solution for 24 hours to see the effect of eventual hydrolytic degradation only. 

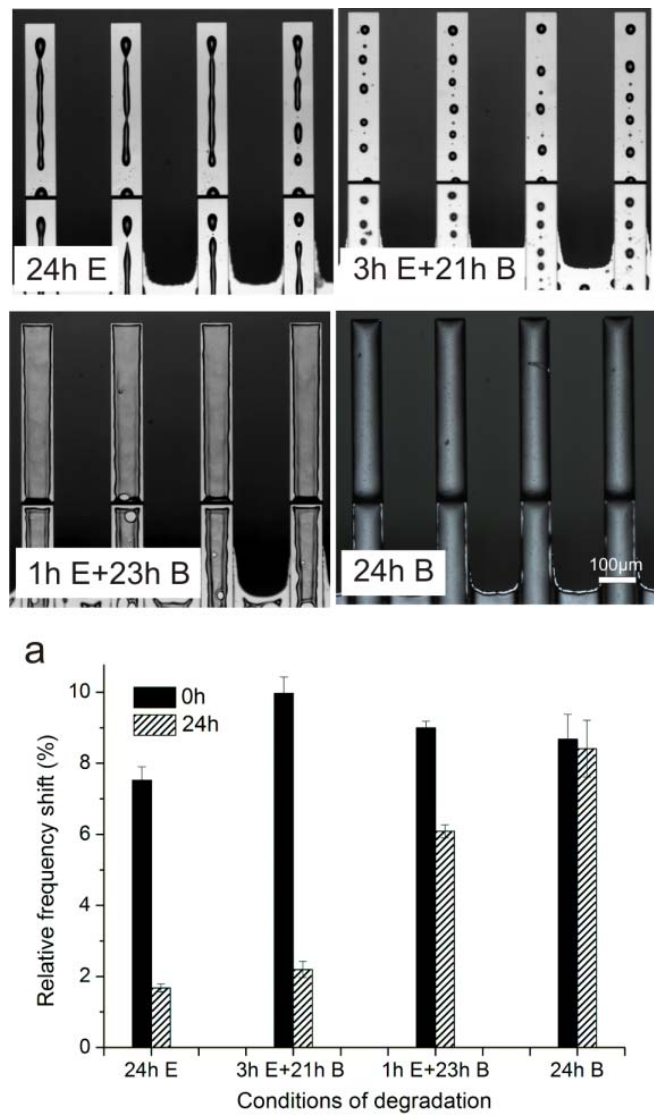

Figure 6. OM images and (a) relative frequency shift of coated cantilevers at different degradation conditions. The scale bar shown in $24 \mathrm{~h} \mathrm{~B}$ is valid for all the OM images. Sample named $24 \mathrm{~h} \mathrm{E}$ is immersed in enzyme solution for 24 hours, $3 \mathrm{~h} \mathrm{E}+21 \mathrm{~h} \mathrm{~B}$ is immersed in enzyme solution for 3 hours and in buffer solution for 21 hours, $1 \mathrm{~h} \mathrm{E}+23 \mathrm{~h} \mathrm{~B}$ is immersed in enzyme solution for 1 hour and in buffer solution for 23 hours and $24 \mathrm{~h} \mathrm{~B}$ is immersed in buffer solution for 24 hours.

From Figure $6 a$ comparing the shift in relative frequency, conditions ' $24 \mathrm{~h} \mathrm{E}$ ' and ' $3 \mathrm{~h} \mathrm{E}+21 \mathrm{~h} \mathrm{~B}$ ' have reached regime III (Figure $2 \mathrm{~h}$ ). Condition ' $1 \mathrm{~h} \mathrm{E}+23 \mathrm{~h} \mathrm{~B}$ ' is still in regime II and condition '24h B' shows an almost negligible frequency shift in 24 hours. OM images of different conditions in Figure 6 showing the PDLLA left on the cantilever surface at the end of 24 hours confirm the frequency shift findings.

Yamashita et al. reported the irreversible adsorption of proteinase $\mathrm{K}$ on the surface of PLLA films and observed that when the enzyme solution was replaced with buffer solution the PLLA film was 
hydrolyzed completely without a decrease in the degradation rate[7]. Li et al. confirmed the observation of adsorption of enzyme on PLLA but observed no enzyme attachment on PDLA[48]. In our study, when the PDLLA coated cantilevers are exposed to enzyme solution for 3 hours followed by immersion in only buffer solution for 21 hours (Condition ' $3 \mathrm{~h} \mathrm{E}+21 \mathrm{~h} \mathrm{~B}$ ', Figure 6), degradation reaction continues uninterrupted as reported by others. But for condition ' $1 \mathrm{~h} \mathrm{E}+23 \mathrm{~h} \mathrm{~B}$ ' when the PDLLA coated cantilevers are exposed to enzyme solution for only 1 hour followed by immersion in only buffer solution for 23 hours (Figure 6), degradation reaction continues for few hours but ultimately stopped unlike the previous. This indicates that in the initial phase, the enzymes require some time to adsorb on the entire PDLLA layer on the cantilever surface. 1 hour as in case of condition ' $1 \mathrm{~h} \mathrm{E}+23 \mathrm{~h} \mathrm{~B}$ ' is too short and thus the enzymatic degradation stops after sometime. In 3 hours the enzymes have sufficient time to attach well to the PDLLA surface and continue to degrade the biopolymer when transferred to buffer solution. Condition ' $24 \mathrm{~h}$ B' shows negligible effect of buffer solution on degradation of the polymer (Figure 6) proving the catalytic behavior of proteinase $\mathrm{K}$ in enzymatic degradation.

\section{CONCLUSION}

Enzymatic degradation of amorphous PDLLA has been investigated using microcantilevers. These devices are an excellent tool to do a detailed analysis of the degradation of thin PDLLA coatings by measuring the resonance frequency of the cantilever before and after degradation. The miniaturized cantilever system is highly sensitive towards biodegradation of minute amounts of polymer, resulting in a fast analysis of the degradation behavior without the need of thermal and chemical acceleration. Degradation rate of the polymer has been estimated by multilayer cantilever theory and finite element simulation where two different rates were observed for lateral and vertical degradation. Bulk degradation rate of $0.24 \mu \mathrm{g} \mathrm{mm}^{-2}$ hour ${ }^{-1}$ was estimated which agrees well with 
other reported values where larger specimen size and longer degradation time were required. We have demonstrated that the enzyme concentration, pre-hydration in buffer, surface morphologies of PDLLA films and adsorption of enzymes influence the rate of enzymatic degradation. An increase in degradation rate is observed with an increase in enzyme concentration. It has also been concluded that pre-hydration in buffer favours the overall enzymatic degradation process. A polymer film with a non-uniform surface degrades faster than the uniform one due to the preference of enzyme attack at film defects. This suggests that surface uniformity is important in biomedical applications. It was also concluded that a threshold time of around 3 hours is required for enzyme adsorption on the polymer surface after which degradation can proceed even in buffer solution. Our study helps to improve the understanding of the degradation behavior of polymer coatings. The approach can be applied to other biopolymers in different degradation conditions for a fast estimation of degradation rate.

\section{ACKNOWLEGDEMENTS}

This research is supported by the Villum Kann Rasmussen Centre of Excellence "NAMEC" under Contract No.65286

\section{REFERENCE}

[1] Henton D, Gruber P, Lunt J, Randall J. Polylactic Acid Technology. Nat. Fibres, Biopolym. Biocomposites, 2005, p. 527-78.

[2] Ulery BD, Nair LS, Laurencin CT. Biomedical Applications of Biodegradable Polymers. J Polym Sci B Polym Phys 2011;49:832-64.

[3] Hayashi T. Biodegradable polymers for biomedical uses. Prog Polym Sci 1994;19:663-702.

[4] Tokiwa Y, Calabia BP. Biodegradability and biodegradation of poly(lactide). Appl Microbiol Biotechnol 2006;72:244-51.

[5] Datta R, Henry M. Lactic acid: recent advances in products, processes and technologies - a review. J Chem Technol Biotechnol 2006;81:1119-29. 
[6] Dan, Scott Gilead D, editor. Degradable polymers: principles and applications. London, UK: Chapman \& Hall; 1995.

[7] Yamashita K, Kikkawa Y, Kurokawa K, Doi Y. Enzymatic degradation of poly(L-lactide) film by proteinase $\mathrm{K}$ : quartz crystal microbalance and atomic force microscopy study. Biomacromolecules 2005;6:850-7.

[8] Engineer C, Parikh J, Raval A. Review on hydrolytic degradation behavior of biodegradable polymers from controlled drug delivery system. Trends Biomater Artif Organs 2011;25:7985.

[9] Chen Q-Z, Harding SE, Ali NN, Lyon AR, Boccaccini AR. Biomaterials in cardiac tissue engineering: Ten years of research survey. Mater Sci Eng R Reports 2008;59:1-37.

[10] Auras R, Lim L, Selke S, Tsuji H. Poly (lactic acid): synthesis, structures, properties, processing, and applications. New Jersey, USA: John Wiley \& Sons, Inc.; 2011.

[11] Kulkarni RK, Moore EG, Hegyeli a F, Leonard F. Biodegradable poly(lactic acid) polymers. J Biomed Mater Res 1971;5:169-81.

[12] Kulkarni A, Reiche J, Lendlein A. Hydrolytic degradation of poly(rac-lactide) and poly[(raclactide)-co-glycolide] at the air-water interface. Surf Interface Anal 2007;39:740-6.

[13] Lyu S, Untereker D. Degradability of polymers for implantable biomedical devices. Int J Mol Sci 2009; 10:4033-65.

[14] Tsuji H, Mizuno A, Ikada Y. Properties and morphology of poly(L-lactide). III. Effects of initial crystallinity on long-termin vitro hydrolysis of high molecular weight poly(L-lactide) film in phosphate-buffered solution. J Appl Polym Sci 2000;77:1452-64.

[15] Tsuji H, Ogiwara M, Saha SK, Sakaki T. Enzymatic, alkaline, and autocatalytic degradation of poly(L-lactic acid): effects of biaxial orientation. Biomacromolecules 2006;7:380-7.

[16] Auras R, Harte B, Selke S. An overview of polylactides as packaging materials. Macromol Biosci 2004;4:835-64.

[17] Li S, Tenon M, Garreau H, Braud C, Vert M. Enzymatic degradation of stereocopolymers derived from 1-, dl- and meso-lactides. Polym Degrad Stab 2000;67:85-90.

[18] Vasanthan N, Ly O. Effect of microstructure on hydrolytic degradation studies of poly (1lactic acid) by FTIR spectroscopy and differential scanning calorimetry. Polym Degrad Stab 2009;94:1364-72.

[19] Azevedo HS, Reis RL. Understanding Enzymatic Degradation of Biodegradable Polymers and Strategies to Control Their Degradation Rate. In: Reis RL, Román JS, editors. Biodegrad. Syst. Tissue Eng. Regen. Med., Florida, USA: CRC Press; 2005, p. 177-202. 
[20] Kikkawa Y, Abe H, Iwata T, Inoue Y, Doi Y. Crystallization, Stability, and Enzymatic Degradation of Poly( 1 -lactide) Thin Film. Biomacromolecules 2002;3:350-6.

[21] Williams DF. Biodegradation of surgical polymers. J Mater Sci 1982;17:1233-46.

[22] Ashley, SL and McGinity J. Enzyme-mediated drug release from poly (d, l-lactide) matrices. Congr Int Technol Pharm 1989;5:195-204.

[23] Rahmouni M, Chouinard F, Nekka F, Lenaerts V, Leroux JC. Enzymatic degradation of cross-linked high amylose starch tablets and its effect on in vitro release of sodium diclofenac. Eur J Pharm Biopharm 2001;51:191-8.

[24] Södergård A, Selin J-F, Näsman JH. Hydrolytic degradation of peroxide modified poly(Llactide). Polym Degrad Stab 1996;51:351-9.

[25] Tsuji H, Ikada Y. Properties and morphology of poly(L-lactide). II. hydrolysis in alkaline solution. J Polym Sci Part A Polym Chem 1998;36:59-66.

[26] Cam D, Hyon S, Ikada Y. Degradation of high molecular weight poly(l-lactide) in alkaline medium. Biomaterials 1995;16:833-43.

[27] Xu L, Crawford K, Gorman CB. Effects of Temperature and $\mathrm{pH}$ on the Degradation of Poly(lactic acid) Brushes. Macromolecules 2011;44:4777-82.

[28] Kikkawa Y, Hirota T, Numata K, Tsuge T, Abe H, Iwata T, et al. In-situ atomic force microscopy observation of enzymatic degradation in poly(hydroxyalkanoic acid) thin films: normal and constrained conditions. Macromol Biosci 2004;4:276-85.

[29] Sumner C, Krause S, Sabot A, Turner K, McNeil CJ. Biosensor based on enzyme-catalysed degradation of thin polymer films. Biosens Bioelectron 2001;16:709-14.

[30] Boisen A, Dohn S, Keller SS, Schmid S, Tenje M. Cantilever-like micromechanical sensors. Reports Prog Phys 2011;74:036101.

[31] Keller SS, Gammelgaard L, Jensen MP, Schmid S, Davis ZJ, Boisen A. Micromechanical sensors for the measurement of biopolymer degradation. 2011 IEEE 24th Int Conf Micro Electro Mech Syst 2011:457-60.

[32] Yamashita K, Funato T, Suzuki Y, Teramachi S, Doi Y. Characteristic Interactions between Poly(hydroxybutyrate) Depolymerase and Poly[(R)-3-hydroxybutyrate] Film Studied by a Quartz Crystal Microbalance. Macromol Biosci 2003;3:694-702.

[33] Wolff O, Seydel E, Johannsmann D. Viscoelastic properties of thin films studied with quartz crystal resonators. Faraday Discuss 1997;107:91-104.

[34] Reiter G, Napolitano S. Possible origin of thickness-dependent deviations from bulk properties of thin polymer films. J Polym Sci Part B Polym Phys 2010;48:2544-7. 
[35] Vogt BD, Soles CL, Lee H, Lin EK, Wu W. Moisture absorption into ultrathin hydrophilic polymer films on different substrate surfaces. Polymer 2005;46:1635-42.

[36] Bose S, Keller SS, Alstrøm TS, Boisen A, Almdal K. Process optimization of ultrasonic spray coating of polymer films. Langmuir 2013;29:6911-9.

[37] Sandberg R, Svendsen W, Mølhave K, Boisen A. Temperature and pressure dependence of resonance in multi-layer microcantilevers. J Micromechanics Microengineering 2005; 15:1454-8.

[38] Schmid S. Electrostatically Actuated All-Polymer Microbeam Resonators - Characterization and Application. Sci Reports Micro Nanosyst Vol6 2009:Der Andere Verlag, Zurich, Switzerland.

[39] Tsuji H, Ishida T, Fukuda N. Surface hydrophilicity and enzymatic hydrolyzability of biodegradable polyesters: 1. effects of alkaline treatment. Polym Int 2003;52:843-52.

[40] Tsuji H, Nishikawa M, Osanai Y, Matsumura S. New Strategy for Controlling Biodegradability of Biodegradable Polyesters by Enzyme-Catalyzed Surface Grafting. Macromol Rapid Commun 2007;28:1651-6.

[41] Reeve MS, McCarthy SP, Downey MJ, Gross RA. Polylactide stereochemistry: effect on enzymic degradability. Macromolecules 1994;27:825-31.

[42] Tsuji H, Miyauchi S. Enzymatic hydrolysis of poly(lactide)s: effects of molecular weight, Llactide content, and enantiomeric and diastereoisomeric polymer blending. Biomacromolecules 2001;2:597-604.

[43] Bikiaris DN, Papageorgiou GZ, Achilias DS. Synthesis and comparative biodegradability studies of three poly(alkylene succinate)s. Polym Degrad Stab 2006;91:31-43.

[44] Liu L, Li S, Garreau H, Vert M. Selective enzymatic degradations of poly(L-lactide) and poly(epsilon-caprolactone) blend films. Biomacromolecules 2000;1:350-9.

[45] Balashev K, John DiNardo N, Callisen TH, Svendsen A, Bjørnholm T. Atomic force microscope visualization of lipid bilayer degradation due to action of phospholipase A2 and Humicola lanuginosa lipase. Biochim Biophys Acta 2007;1768:90-9.

[46] Balashev K, Jensen TR, Kjaer K, Bjørnholm T. Novel methods for studying lipids and lipases and their mutual interaction at interfaces. Part I. Atomic force microscopy. Biochimie 2001;83:387-97.

[47] Tsuji H, Ishizaka T. Preparation of porous poly(epsilon-caprolactone) films from blends by selective enzymatic removal of poly(L-lactide). Macromol Biosci 2001;1:59-65.

[48] Zhao Z, Yang L, Hua J, Wei J, Gachet S, El Ghzaoui A, et al. Relationship between enzyme adsorption and enzyme-catalyzed degradation of polylactides. Macromol Biosci 2008;8:2531 . 
